\title{
Cast Iron Rolls for Steel Rolling in Japan*
}

\author{
By Kakunosuke Miyashita**
}

\section{Synopsis}

This paper outlines the present situation of cast iron rolls in Japan, which have shown remarkable development in recent years, and refers to the field of various rolling operations to which these cast iron rolls are applied.

\section{Preface}

The major characteristic of steel production in postwar Japan is its remarkable growth. As for the production of crude steel, this country produced 560,000 tons in 1946, and in 1953 exceeded 7,650,000 tons, the maximum output in prewar years. The total tonnage reached 28 million tons in 1961.

The remarkable expansion in steel production, seen in the production of pig iron and steel material as well, is supported mainly by the growth of domestic demands. This high production has been attained by the "rationalization of equipment" both in the melting and rolling fields that was carried out in two stages after 1951

As for the rationalization of equipment in the rolling fields, the machines were renewed or newly installed at first by the introduction of foreign techniques and by the purchasing of modern machines. Secondly, reduction of various expenses was accomplished by mass-production. Rationalization of strip mills and such processing machines as continuous equipment for galvanized iron sheet manufacture was remarkable. Also, the rationalization of continuous wire-rod mills and equipment for butt-welded tubing was prominent.

Such rationalization of rolling equipment and the accompanying enhancement of rolling efficiency resulted from the fact that high-quality rolls were required. It is worthwhile to study the development of the manufacturing techniques for rolls as well as the improvement in their quality. As for sand rolls, definite chilled rolls and indefinite chilled rolls which have long been produced in Japan, attempts were made to enlarge them by developing a new manufacturing method. And also, spheroidal graphite cast iron which was developed in 1945 was successfully used in the manufacture of spheroidal graphite iron rolls. Further, Adamite rolls which had been used in foreign countries for many years were produced for use in meeting the increasing demands for large sections, thus extending the applications of cast iron rolls.

Cast iron rolls are also classified according to the metals used in their manufacture. The number of types of rolls in actual operation is still increasing.

This paper treats in outline form the present manufacturing methods and properties of cast iron rolls that have been developed thus far and refers to the rolling field to which these rolls are being applied according to their properties.

\section{Properties of Cast Iron Rolls and Summary of Manufacturing Processes}

Cast iron rolls that are presently used for steel rolling are classified into Adamite rolls, sand rolls, definite chilled rolls, indefinite chilled rolls and spheroidal graphite iron rolls (referred to as S.G. iron rolls hereafter).

These are divided further into plain cast iron rolls or alloy cast iron rolls, etc., according to their content of alloy elements such as $\mathrm{Ni}, \mathrm{Cr}$ and Mo. Moreover, the abovementioned rolls are named as "double poured cast iron rolls" when the "double pouring method" is employed in their casting. This will be discussed further later in this paper.

Table 1 shows the classification of these cast iron rolls according to their materials, outlining the fields of steel products where these rolls are applied. However, the types of cast iron rolls vary greatly. Thus, it has become extremely difficult to select a suitable roll for operating conditions because the materials shown here are being further subdivided and produced so as to meet individual rolling conditions. Therefore, it is indispensable in selecting proper rolls to fully understand their special qualities. This problem is being solved by cooperation between the users and the manufacturers.

The undermentioned is an outline of the present roll manufacturing processes and the properties of the rolls, followed by the different applications of cast iron rolls at present in Japan, classified according to each rolling mill.

\section{Summary of Manufacturing Process for Cast Iron Rolls}

As for the melting furnace, air-furnaces are still used largely because large amounts of molten metal can be managed at one time, large material such as discarded rolls can be charged, repair and maintenance on the furnaces can be conducted comparatively easily and chemical components can be freely adjusted during the melting process. By improving combustions, melting at higher temperatures has been made possible so that low-carbon cast iron rolls such as Adamite rolls can be produced easily.

Although some definite chilled rolls, S.G. iron rolls and calender rolls are produced by cupolas, the rate of use for cupolas is small compared with air-furnaces. Cast iron rolls are generally cast by the "bottom-pour swirl method" into the casting mold shown in Fig. 1. This method, however, is a sort of centrifugal action throw and does not differ with

\footnotetext{
Japanese text was printed in “Tetsu-to-Hagané” (Journal, Iron \& Steel Institute, Japạn) Vol. 47, 1961, pp. 1631-1643.

** Managing Director, Dr. Eng., Hitachi Metal Industries, Ltd.
} 
casting method itself.

In case strength and hardness are generally required in cast iron rolls at the same time, the double pouring method is in a great many cases employed for the purpose of removing the residual stress. The casting mold shown in Fig. 2 is used in this method.

Molten metal having the qualities of high hardness and resistance to wear is poured into this mold, when the barrel surface of the roll contacting the metal mold (chiller) is solidified one to four inches deep, after the duration of the pre-set time based on the roll diameter and its useful amount.

Secondly, molten soft cast iron is poured into the mold through the same gate before the inner part of the barrel and the top and bottom journals in the sand mold have solidified. Then the first molten metal of hard quality in an unsolidified state is allowed to flow out through the spout at the top

Table 1. Cast iron rolls: Description and uses

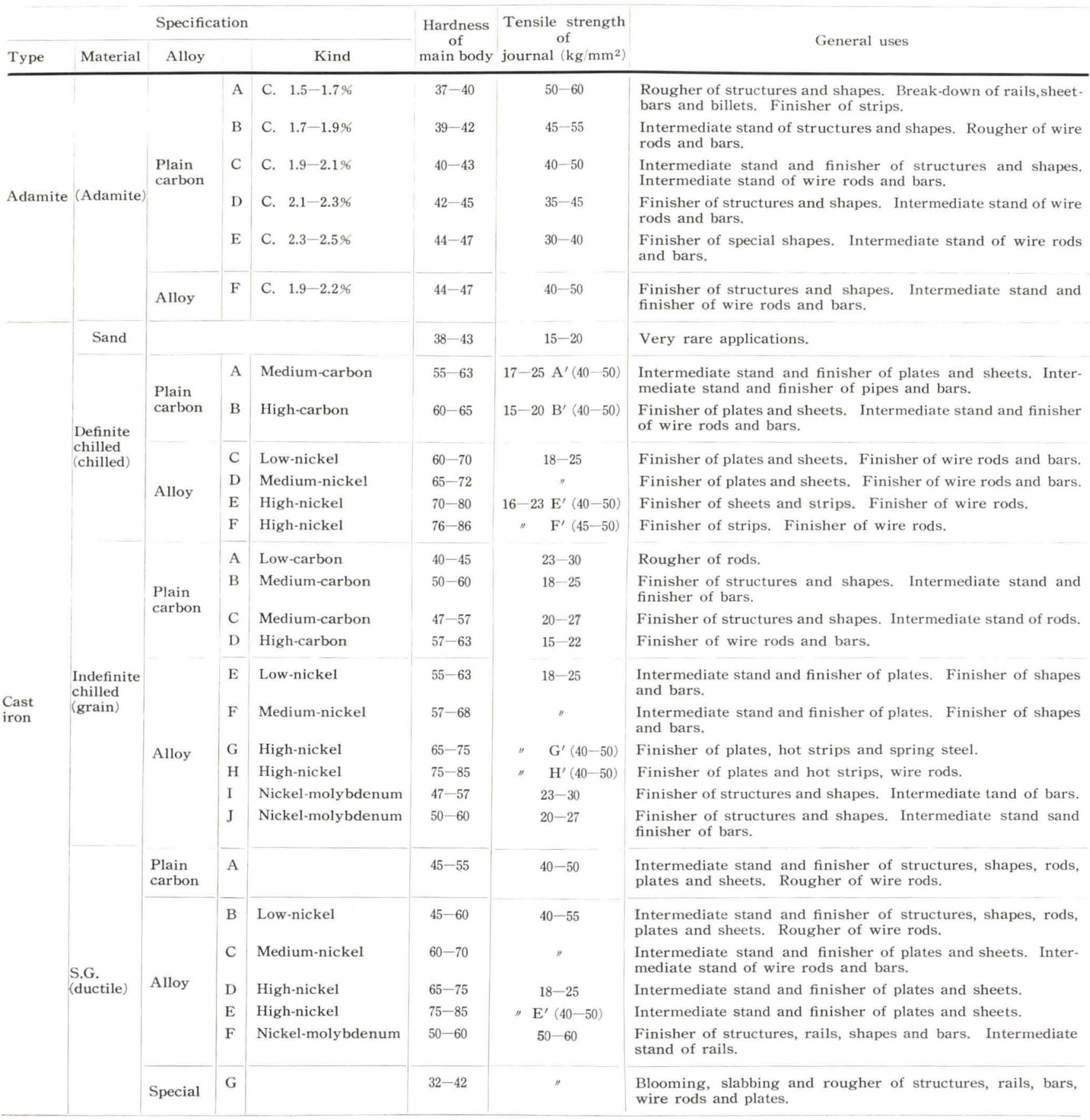


journal or is pushed upward to the head. Thus, a roll with a body shell of high hardness and resistance to wear and an inner section and top and bottom journals of soft quality but enough strength is produced by this method. This product is known generally as a "double-poured cast iron roll."

This process has become a generalized casting method, although special techniques in pouring, in obtaining the proper outer shell and the balancing of chemical contents of molten metals between the outer shell and its inner part are required.

Gray cast iron is generally used for the secondpour molten metal, but S.G. iron is used in many cases because much strength has recently been demanded especially at the journal.

In this case, the tensile strength at the journal reaches to 40 to $50 \mathrm{~kg} / \mathrm{mm}^{2}$, so that the roll can be used in a stand where high rolling loads occur.

The casting mold shown in Fig. 1 is generally made of a single block of metal chiller for the barrel and a sand mold for top and bottom journals.

When deep grooves and the same hardness both at

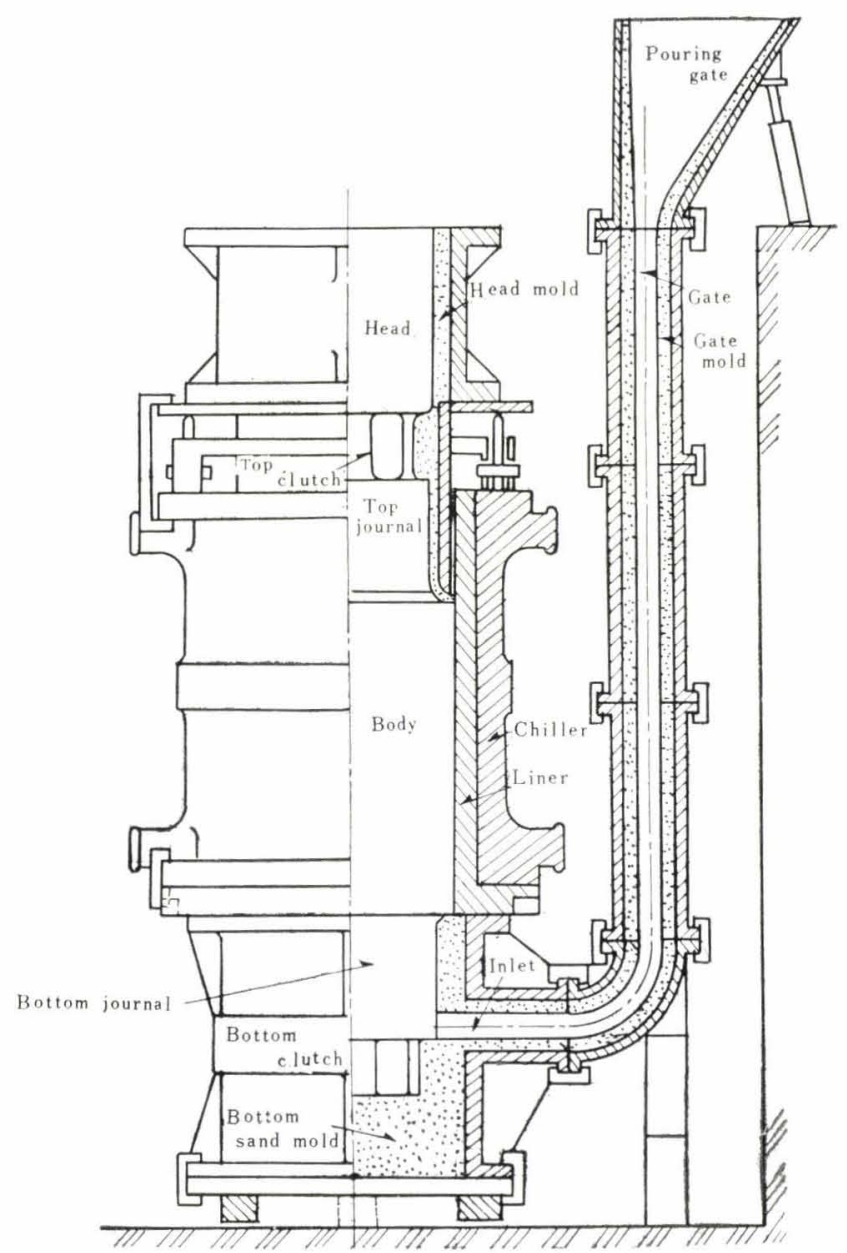

Fig. 1. Plain roll mold the groove bottom and the flange surface are required, however, rolls cast with chill rings-so to speak-are produced in many cases where metal rings corresponding to the groove shape are installed inside the metal chiller mold. Also, for rolls cast at high temperatures such as Adamite rolls, a sand mold with sand-lining on the surface of its ring chiller as shown in Fig. 3 is used. This type of casting mold is especially used in making S.G. iron rolls with low hardness. However, metal chillers made from one block are used for ordinary S.G. iron rolls.

Heat treatment for these cast iron rolls is being studied, put into practical use in order to improve the strength and to increase the resistance to heat that are defects of cast iron rolls.

As for the testing method, the application of the supersonic method for casting iron rolls is a noteworthy development which is playing an important role in preventing rolling accidents, and obtaining the same results as those of steel rolls.

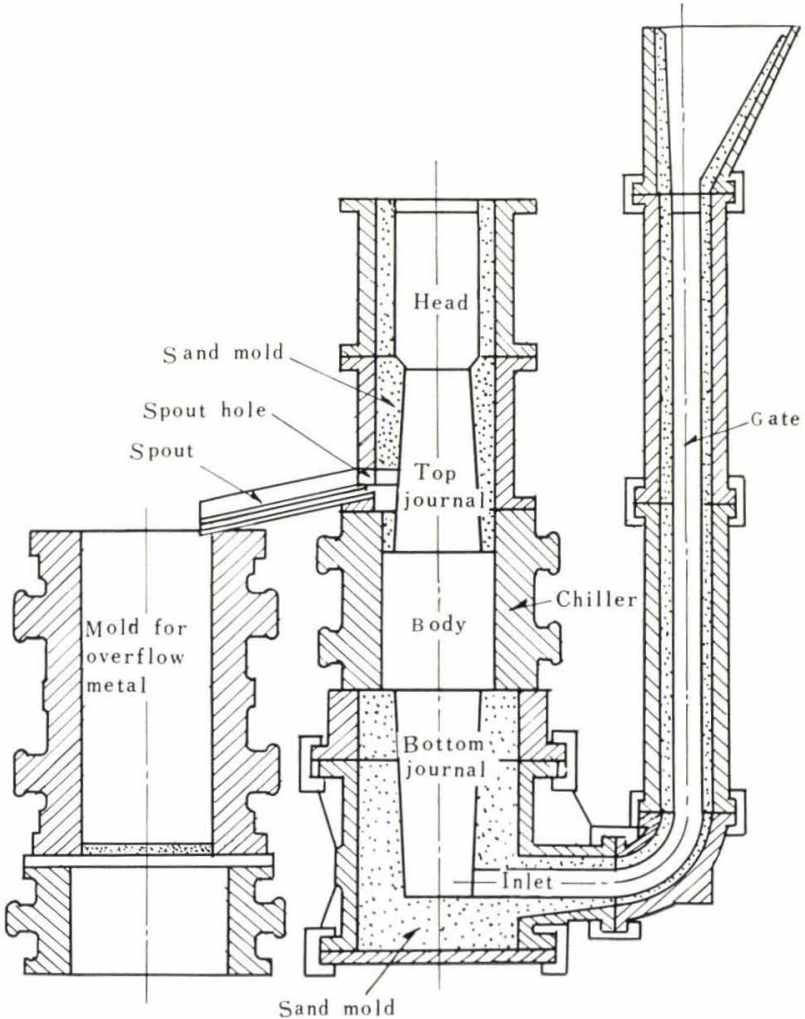

Fig. 2. Roll mold for double-pouring method 


\section{Properties of Cast Iron Rolls}

\section{a. Definite Chilled Roll}

This roll, generally called "a chilled roll" in Japan, has as long a history as the sand roll. In order to make chilled rolls, molten cast iron containing proper components is poured into a metal mold to make the barrel surface into white cast iron and the inner and journal parts into graphitized cast iron, by utilizing the differences in cooling speed. The characteristic of chilled rolls is the fact that the barrel surface is made of white cast iron (chilled) and does not contain graphite. Therefore, it has high resistance to wear compared with other cast iron rolls and finishes the rolled material to a glassy surface. But it is subject greatly to heat cracks because of free cementation. Accordingly, it is generally installed in the finishing stand which receives less thermal shock. Also, there is a mottled area inside the white cast il on part (i.e. chilled part) where graphite appears,

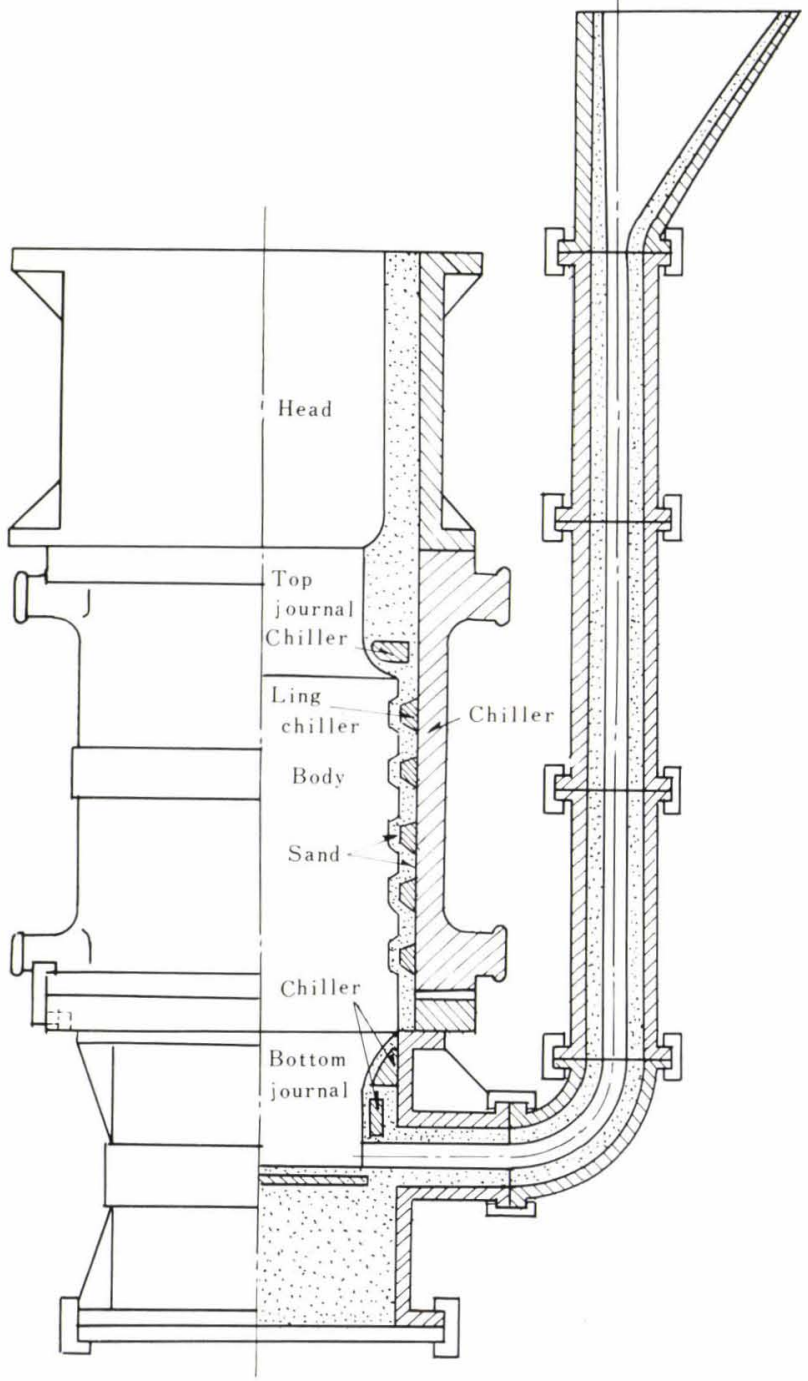

Fig. 2. Sand mold for caliber roll so that the hardness is lowered to a great degree. Since the chill depth is usually about one inch, it is generally used for finishing plates and sheets and also for wire rods and bars in which case shallow grooves are cut.

When applied to a finishing stand for large bars, pipe and tube rolling etc., however, a casting mold with metal rings is used, since deep grooves are required, in order to give the same hardness both to the groove bottom and to the flange surface. The double-pour casting method is employed to retain the strength. This is generally termed "a roll cast with chill rings". Chilled rolls without alloy elements such as $\mathrm{Ni}$ and $\mathrm{Cr}$, etc., are called "plain carbon chilled rolls" whose hardness is about 55 to 65 Shore. In order to increase the hardness, alloy elements such as $\mathrm{Ni}$ and $\mathrm{Cr}$, etc., are added, thus changing the structure of the matrix of white iron into pearlite, sorbite, troostite, bainite and martensite. In this way, the hardness is enhanced to approximately 85 Shore. Rolls of great hardness are produced by the double-pour method, since they are brittle and have a high residual stress. These chilled rolls containing $\mathrm{Ni}$ and $\mathrm{Cr}$ are called "alloy chilled rolls".

\section{b. Indefinite Chilled Roll}

This roll is generally called "a grain roll” in Japan, and differs from chilled rolls in that the former contains flaky graphite up to its barrel surface. Grain rolls also are generally cast in a metal mold in order to cool the barrel surface rapidly, so that fine flaky graphite appears on the barrel surface and becomes coarse and increases as it goes toward the roll center.

Therefore, the hardness gradually lessens from its surface to the inner part, but there is no quick falling of hardness as in the mottled part in chilled rolls. Accordingly, when the surface hardness is the same, the hardness inside is higher in grain rolls than in chilled rolls. Thus, grain rolls are used in structural and shape mills where grooves are generally machined.

These grain rolls also are widely used even in strip and plate mills because flaky graphite has the so-called "buffer action" to lessen the cause for heat cracks or spallings in spite of the fact that they are rather inferior to chilled rolls as far as the finished surface and brightness of rolled products is concerned.

As for their hardness, alloy grain rolls, containing alloy elements such as $\mathrm{Ni}, \mathrm{Cr}$ and $\mathrm{Mo}$, have the maximum hardness up to 85 Shore. The hardness of plain carbon grain rolls, not containing alloy elements, ranges from 40 to 63 Shore by changing their carbon content and the amount of both free cementite and graphite.

In this case, however, the surface hardness is 
raised by increasing the carbon content, the hardness inside drops remarkably on the contrary and the mechanical properties become inferior. Accordingly, high-carbon plain rolls are used in plate and sheet mills, wire-rod mills, and light bar mills, for their outer layer only. And in structural mills, where deep grooves in the roll are required, lowcarbon grain rolls which have properties of less hardness dropping and enough strength are employed. Similar to chilled rolls, in order to maintain high hardness, the double-pour casting method is used for grain rolls, for employment under high rolling loads and for cutting deep grooves.

c. Sand Roll

This roll is produced by casting the proper molten components into a sand mold, in which the roll is slowly cooled so that it shows an even structure as a whole. Since it contains comparatively large flaky graphite and less free cementite, there is no fall of hardness, which is approximately 38 to 45 Shore from the roll surface to its inner area.

Because of the appearance of grain rolls and S.G. cast iron rolls, this sand roll has not been used much lately. Previously it was used in the finishing stands of the structural and shape mills and in the roughing and intermediate stands of wire rod, plate and sheet mills.

\section{d. Spheroidal Graphite Iron Roll}

Although the above-stated cast iron rolls have been appreciated and used for their greater resistance to wear compared with cast steel rolls, the worst defects were that they were brittle and often caused breakage.

As soon as spheroidal graphite iron, having properties of both ductility and resistance to wear, was developed in 1945, research began for using it in rolls. The product has been in use since 1953. At first, these rolls were used in light and medium structural mills for making wire rods and bars. Then they gradually entered the field of large structural mills. Here its ductility was praised as superior to that of sand rolls or grain rolls and its resistance to wear as superior to that of steel rolls. Next they began to be installed in blooming mills following improvements in manufacturing methods and heat treatment. They showed an excellent performance in actual operation.

At present, they are widely used in all fields of steel rolling.

In this country, in order to satisfy the necessity for balancing the ductility and wear resistance, these spheroidal graphite iron rolls are generally produced by using an air-furnace to accurately adjust the chemical contents and to prevent the mixing of impurities in the molten metal harmful for $\mathrm{Mg}$-treatment. It is possible to make blooming rolls, weigh- ing up to 40 to 50 tons, in this furnace.

The casting mold is the same as that for other cast iron rolls, but in the case of blooming mill rolls or slabbing mill rolls, S.G. iron rolls with knurling are used because the degree of taking in the material or slipping is more important problem than that of resistance to wear.

The characteristic of S.G. iron rolls is that the graphite is spheroidal although it appears on the surface just as in indefinite chilled rolls. Accordingly, it can be stated that the structure of the roll surface and the degree of hardness dropping inward are about the same as in indefinite chilled rolls, but their chemical content differs somewhat from that of other cast iron rolls.

Usually, the carbon and silicon content is higher and $\mathrm{Cr}$ is adjusted in a lower degree in order to control the cause of white cast iron and to graphitize the inner part of the rolls for carrying out $\mathrm{Mg}$ treatment. For example, a high-carbon material is suitable for plate mill rolls or wire rod mill rolls in which the chief object aimed at is surface hardness, but there is no cause for a lowering of strength due to the increase of carbon. On the contrary, in the case of structural mill rolls with deep grooves, rolls containing high carbon are not favored because the increase of graphite inside is controlled to solve the problem of a lessening of hardness.

S.G. iron rolls are also classified into alloy S.G. iron rolls in which the hardness is raised by hardening the matrix with such alloy elements as $\mathrm{Ni}, \mathrm{Cr}$ and Mo and plain carbon S.G. iron rolls containing no alloy elements. Their hardness ranges from 30 to 80 Shore. Naturally, the double-pour casting method is employed in this case, and generally the rolls are so designed as to have properties suitable for each specified use by performing various heattreatments after casting.

Thus, at present in Japan, S.G. iron rolls are widely used in every field of steel rolling. It is expected that they will be improved and further developed in future.

e. Adamite Roll

This type of rolls has been used for many years in foreign countries. In this country also, low-carbon Adamite rolls have been used in light and medium structural and shape mills for a long period and have been developed greatly as the demand for large sections increased after 1948. Adamite rolls are placed between cast steel rolls and cast iron rolls, and are classified from the standpoint of chemical content, especially carbon content, and microstructure. Accordingly, in hardness and mechanical properties, they have, so to speak, a neutral quality between the two types above. Their as-cast structure is similar to that of white cast iron of low-carbon 
consisting of pearlite matrix, eutectic cementite and eutectoid cementite. Since they are still brittle at this stage, heat treatment is performed in order to give them ductility by spherodizing pearlite and also by cutting and spherodizing the eutectoid cementite which is developed dendritically. But, even through this heat treatment, eutectoid cementite remains as large lumps. Accordingly, the roll of high-carbon type although having high hardness is brittle and shows properties similar to cast iron, while the roll of low-carbon has rich ductility and shows properties similar to those of cast steel rolls although hardness is lower due to less eutectic cementite.

Generally rolls containing carbon of $1.2-2.5 \%$ are produced and low-carbon rolls are used in roughing stands, and high-carbon rolls in finishing stands.

By adjusting carbon content, hardness ranging from 38 to 50 Shore can be obtained and the whole body of a roll will have uniform quality. No lessening of hardness toward the center can be detected. For these reasons they are being used in structural mills where uniform wear of grooved parts is required.

Although hardness can be raised by adding alloy elements such as $\mathrm{Ni}$ and $\mathrm{Mo}$ in the case of Adamite rolls also, the increase in hardness over a wide span cannot be expected before heat-treatment is carried out in manufacturing. Recently, it has been made possible to hinder the cause for development of heat cracks by a small amount of spheroidal graphite on the surface. Adamite rolls are beginning to be used as finishing work rolls in hot strip mills.

\section{Applications of Cast Iron Rolls}

It is difficult to state in detail in what fields the various cast iron rolls mentioned in the previous chapter are being used, because each operational condition for each rolling mill differs. However, its general tendencies are summarized and shown in Table 2.

\section{Blooming and Slabbing Mills}

At these mills, the chief emphasis is placed on improvement of rolling efficiency rather than on the quality of the surface of products. Therefore, rolls for these mills are required to have properties of resistance to violent repeated thermal shocks and high rolling loads. Formerly, cast steel rolls were used which had the defect of causing comparatively deep heat cracks locally on the roll surface which in turn caused fatigue breakage and the tendency to stick to the steel material causing surface roughening and a large quantity of wear.

Recently, from the standpoints of both improvement in these defects and economy in expenditures, S.G. iron rolls of 30 to 40 Shore have been used.
They show a rolling performance of 1.5 to 2 times that of cast steel type rolls.

Therefore, a general entry of S.G. iron rolls into this field is now being considered.

\section{Structural Mills}

Although there are many kinds of sections and their forms vary greatly, rolls for structural mills are required to have properties of high hardness, retaining it not only at the surface but in their inner parts, and high resistance to wear inside their groove. In addition, they must be made of a strong material in order to prevent accidents such as barrel breakage or flange chippings, etc.

Due to the above reasons, special S.G. iron rolls of 30 to 40 Shore are generally used in the roughing stand of light and medium structural mills. Especially when resistance to wear at the groove bottom is required or there is a fear of breakage due to the lack of strength, a low-carbon Adamite roll can

Table 2. Uses of cast iron rolls

\begin{tabular}{|c|c|c|}
\hline Type of mills & Stands & Various cast iron rolls used \\
\hline Blooming & & S.G. Iron "G" \\
\hline Slabbing & & S.G. Iron "G", \\
\hline $\begin{array}{l}\text { Structural } \\
\text { Light }\end{array}$ & $\begin{array}{l}\text { Roughing } \\
\text { Intermediate } \\
\text { Finishing } \\
\text { Roughing } \\
\text { Intermediate } \\
\text { Finishing } \\
\text { Roughing } \\
\text { Intermediate } \\
\text { Finishing }\end{array}$ & 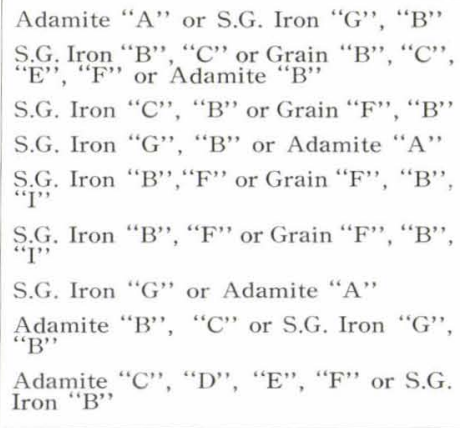 \\
\hline Rail & $\begin{array}{l}\text { Roughing } \\
\text { Intermediate } \\
\text { Finishing }\end{array}$ & $\begin{array}{l}\text { Adamite "A" } \\
\text { S.G. Iron " } F ", \text { ". } B \text { " or Adamite "B", } \\
\text { Grain "I", "J", or S.G. Iron "F", "B", } \\
\text { or Adamite "D", }\end{array}$ \\
\hline Merchant & $\begin{array}{l}\text { Roughing } \\
\text { Intermediate } \\
\text { Finishing }\end{array}$ & 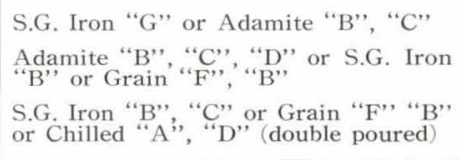 \\
\hline Billet \& bar & $\begin{array}{l}\text { Roughing } \\
\text { Intermediate } \\
\text { Finishing }\end{array}$ & 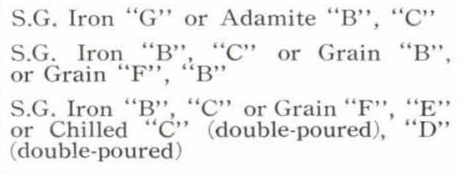 \\
\hline Wire rod & $\begin{array}{l}\text { Roughing } \\
\text { Intermediate } \\
\text { Finishing }\end{array}$ & $\begin{array}{l}\text { Adamite "B", S.G. Iron "G" or "B", } \\
\text { or Grain "A," } \\
\text { S.G. Iron " A", "B", "C", "D" or Grain } \\
\text { "C", "D" } \\
\text { Chilled "C', "D", "E", (double-poured) } \\
\text { or "F" (double-poured), or Grain "G," } \\
\text { (double-poured), "H" (double-poured), } \\
\text { "D". }\end{array}$ \\
\hline
\end{tabular}


be selected.

Although S.G. iron rolls of 50 to 58 Shore are used at the intermediate stand generally, rolls of 65 Shore also are employed where resistance to wear is especially needed. Also in case there occur heavy heat cracks, indefinite chilled rolls of 60 to 70 Shore are used. Adamite rolls of 40 to 45 Shore are selected in case there is danger of breakage due to the lack of strength.

At the finishing stand, rolls similar to those applied in the intermediate stand are used. But various types of rolls are combined according to the shapes of products to use the best characteristic of each.

Generally speaking, cast steel rolls have been used in heavy structural mills where enough strength and deep grooves are required. The entry of Adamite rolls into this sphere has been extensive and S.G. iron rolls with low hardness have been in many cases employed recently.

\section{Rail Mills}

Although the same method of application as for structural mills can be used, various roll materials are combined since they are required to have special shapes and complicated grooves.

Generally, Adamite rolls are used in the roughing stand and S.G. iron rolls of 50 to 60 Shore containing $\mathrm{Ni}$ and $\mathrm{Mo}$ are used in the intermediate stand to solve the problem of strength and prevention of heat cracks.

From the standpoint of resistance to wear, alloy indefinite chilled rolls with low carbon are being used in the finishing stand.

\section{Merchant Mills}

\section{Billet and Bar Mills}

Rolls used for these mills are of about the same tendency; S.G. iron rolls of low hardness, replacing conventional cast steel rolls, and low-carbon Adamite rolls are used in the roughing stand.

For the intermediate stand, Adamite rolls and S.G. iron rolls of 50 to 55 Shore are used where there is a cause for high rolling load. Indefinite chilled rolls of 60 to 70 Shore are used where there are low rolling loads.

Different materials are used in the rolls installed in the finishing stands according to the types of steel products manufactured. S.G. iron rolls of 55 to 65 Shore and indefinite chilled rolls of 70 to 75 Shore are ordinarily used. Especially for finishing round bars, double-poured chilled rolls of 60 to 70 Shore are used where groove bottoms are required at the same time.

\section{Wire Rod Mills}

Since the number of stands and the rolling speed have been increased with the development of high speed mills for wire rods, high resistance to wear is generally desired. In roughing stands, Adamite rolls, S.G. iron rolls of 40 Shore and occasionally indefinite chilled rolls of low hardness have been used, replacing cast steel rolls.

At the intermediate stand, S.G. iron rolls with a comparatively high hardness, 50 to 55 Shore, or indefinite chilled rolls with a hardness of 60 to 65 Shore are being used.

S.G. iron rolls with 65 to 70 Shore and alloy chilled rolls with 65 to 70 Shore are used in the first half of the finishing stands. In the latter half, alloy chilled rolls with 70 to 75 Shore, and alloy chilled rolls (double-poured) especially for the last finishing stand are being employed.

\section{Universal Shape Mills}

Cast steel rolls for roughing stands, S.G. iron rolls of low hardness and Adamite rolls for intermediate and horizontal stands of the finishing train are being produced. Rolls of this type are expected to be further improved in the future in Japan.

\section{Sheet Mills}

Sheet mills in Japan are gradually decreasing as modern hot strip mills develop. However, they are still of practical use for rolling extremely thin steel plates.

For their roughing stands, sand rolls or plain chilled rolls (hot rolls) with a hardness of about 57 to 60 Shore just before their discard have usually been used. Recently, however, S.G. iron rolls with about 45 Shore have been successfully employed.

For finishing stands, a change is occurring from plain to alloy chilled rolls (double-poured) with a hardness of about 65 Shore for the purpose of finishing glossy surfaces, because materials for rolling have become to be limited to extremely thin plates, although plain chilled rolls with a hardness of about 60 Shore have been used.

Alloy chilled rolls with a hardness of 80 Shore are still employed for cold skin pass mills.

\section{Hoop Mills}

Although hoop products belong to sheets, products with narrow width are called hoops, distinguishing them from those produced by strip mills.

The finished surface of hoops is inclined to be more plain and glossy compared with the products produced with strip mills. Therefore, alloy chilled rolls (double-poured) with a hardness of 80 to 85 Shore 
are used in the finishing stand, because the rolled surface made by indefinite chilled rolls with a hardness of about 80 Shore is unsatisfactory as in the case of hot strip mills.

Rolls with a higher hardness than before are gradually being put into use due to the fact that the surface of finished products depends not only upon the finishing stand rolls but upon the degree of surface roughening of the rolls at the roughing and intermediate stands. In the latter roughing stands where cast steel rolls were used, S.G. iron rolls with a hardness of 45 to 55 Shore are now being employed. For intermediate stands, alloy indefinite chilled rolls (double-poured) with a hardness of 65 Shore or alloy chilled rolls (double-poured) are employed and better results are being obtained.

\section{Strip Mills}

Rolls of the cast iron type are used as working rolls at the roughing and finishing stands; and for back-up rolls, cast steel type rolls are being employed.

Mainly indefinite chilled rolls with a hardness of about 80 Shore are used as working rolls in the finishing stands. Chilled type rolls are rarely employed.

Rolls of high hardness to be used in the latter half stands of the finishing train are favored from the standpoint of wear, press marks, and surface roughening. But an enhancement of the hardness leads to an increase of accidents such as spalling or heat cracks.

Concerning the rolls used at the first half of finishing train, where heavy thermal shocks occur, heat crack is easily caused in such rolls of high hardness as used in the latter half stands, and scales are pressed in these cracks to cause scale banding.

Previously it was a practice to use such rolls in the first half of the finishing train that had been installed in the latter half and thus had become smaller in diameter. Recently, however, the tendency to apply rolls of different materials to the first and the latter halves of the finishing train is becoming more and more pronounced. Cast steel rolls with a hardness of 45 to 50 Shore and high alloy S.G. iron rolls (50 Shore) are beginning to be used in the first half and better results are being gained.

Also, instead of cast steel rolls, special Adamite rolls having spheroidal graphite of 45 to 50 Shore were produced and put into a trial use, showing better rolling efficiency than that of cast steel rolls.

For the working rolls of roughing stands, indefinite chilled rolls with a hardness of 70 Shore were formerly used, but S.G. iron rolls have recently been introduced just as in the case of the first half of the finishing train.

\section{Plate Mills}

The major portion of plates having a thickness of 3 to $6 \mathrm{~mm}$ is produced by a Lauth 3-high mill. Although chilled rolls with a hardness of 60 to 63 Shore have been used for this mill, alloy chilled rolls with a hardness of about 70 Shore to decrease the cause of press marks and wear and indefinite chilled rolls with a hardness of 65 to 70 Shore to prevent spalling are being used with good results.

For floor plate, S.G. iron rolls with a hardness of 65 Shore are used to prevent cracks at such checkered parts as the top roll where checkers are machined. They are performing better than the chilled rolls formerly applied.

For rolling plates of more than $6 \mathrm{~mm}$ in thickness, a 4-high reversing mill is used, in which indefinite chilled rolls with a hardness of 65 to 80 Shore are being employed as working rolls and showing good results.

\section{Pipe and Tube Mills}

Cast iron rolls are usually employed in a plug mill rolling mill. Plug main rolls, because deep grooves are required, are grooved chilled rolls (doublepoured) with a hardness of 60 Shore cast with chill rings or of alloy indefinite chilled rolls of about 65 Shore. The finished surface of pipes rolled by grooved chilled rolls is extremely glossy.

Pipes rolled by main rolls are processed through reeler rolls made of chilled cast iron with a hardness of 60 to 65 Shore and then their outside diameter is adjusted by chilled rolls of 65 to 70 Shore or indefinite chilled rolls and are further corrected and finished by straightening rolls made of chilled cast iron of 75 Shore.

\section{Cold Tandem Mills and Temper \& Skin-Pass Mills}

Working rolls for the above mills are presently being researched although the actual performance by cast iron type rolls has not been obtained yet.

For back-up rolls of temper and skin-pass mills, indefinite chilled rolls (double poured) with a hardness of about 75 Shore are being employed and showing an efficiency of $600 \%$ compared with steel rolls. It is expected that cast iron rolls will enter this field in the near future. It is also presumed that the time will come in the near future when cast iron rolls improved as back-up rolls or working rolls of tandem and skin-pass mills will replace steel rolls. 


\section{Conclusion}

This report has outlined the processes, properties and uses of cast iron rolls developed in Japan since World War II. As a result of the fact that development of manufacturing techniques for cast iron rolls has brought improvements in their mechanical properties, the field of use of the present cast iron rolls in Japan has been made much wider. More economical cast iron rolls are being used with good results where expensive steel rolls have been once employed.

The exploitation and manufacture of spheroidal graphite cast iron rolls and Adamite rolls have brought about the development of cast iron rolls in Japan.

Increase of efficiency, accompanied by the rationalization of equipment in the rolling department depends solely on the quality of the rolls.

Manufacturers of cast iron rolls are always trying to supply excellent rolls for the most suitable stands, conforming closely to their users. It is a proposition given to makers of cast iron roll to research theoretically as well as practically in order to step up with improvement in rolling technique that will still more develop hereafter. And a performance of this proposition leads inevitably to the development of cast iron rolls in Japan. 